\title{
A GARANTIA DO \\ CONTEÚDO ESSENCIAL DO \\ DIREITO FUNDAMENTAL \\ À LIBERDADE DE \\ LOCOMOÇÃO DOS \\ ADOLESCENTES: ANÁLISE \\ DE UMA DECISÃO JUDICIAL
}

THE GUARANTEE OF THE ESSENTIAL CONTENT OF THE FUNDAMENTAL RIGHT TO FREEDOM OF MOVEMENT OF ADOLESCENTS: ANALYSIS OF A JUDICIAL DECISION

LA GARANTÍA DEL CONTENIDO ESENCIAL DEL DERECHO FUNDAMENTAL A LA LIBERTAD DE CIRCULACIÓN DE LOS ADOLESCENTES: ANÁLISIS DE UNA DECISIÓN JUDICIAL

\section{Ana Carla Coelho Bessa ${ }^{1}$ Nestor Eduardo Araruna Santiago²}

1 Doutora e Mestre em Direito Constitucional pelo Programa de Pós-Graduação Stricto Sensu em Direito Constitucional da Universidade de Fortaleza (UNIFOR). Professora de Filosofia do Direito, Hermenêutica Jurídica e Teoria da Constituição. Especialista em Abordagem Sistêmica da Família (UNIFOR), Psicopedagogia e Educação Inclusiva, com Formação em Direito Penal (FESAC/CE), Justiça Restaurativa (AJURIS/RS) e em Mediação de Conflitos (UNIFOR/COLUMBIA UNIVERSITY). Advogada. E-mail: coelhobessa@gmail.com

2 Pós-Doutor em Direito pela Universidade do Minho, Portugal. Doutor, Mestre e Especialista em Direito pela Universidade Federal de Minas Gerais (UFMG). Professor do Programa de PósGraduação I em Direito Constitucional da Universidade de Fortaleza (Unifor). Líder do Grupo de Pesquisa "Tutela penal e processual penal dos direitos e garantias fundamentais" (LACRIM - Laboratório de Ciências Criminais) da Unifor. Professor (Graduação) da Faculdade de Direito da Universidade Federal do Ceará (UFC). Coordenador Regional do Instituto Brasileiro de Processo Penal (IBRASPP). Advogado criminalista. E-mail: nestoreasantiago@gmail.com 
Resumo: Trata-se de estudo de acórdão favorável a adolescente ao qual havia sido aplicada medida socioeducativa de internação pela prática de ato infracional equiparado ao tráfico de entorpecentes. A análise teve como parâmetro o direito fundamental à liberdade de locomoção e à teoria do conteúdo essencial dos direitos fundamentais. Examinou-se o direito à liberdade de locomoção a partir da Doutrina da Proteção Integral, que concede ao adolescente a prioridade na proteção dos Direitos Fundamentais. Observou-se que a decisão seguiu a interpretação estrita da norma infraconstitucional regulamentadora da obediência ao princípio constitucional da excepcionalidade quando da aplicação, à criança ou ao adolescente, de qualquer medida privativa da liberdade. Concluiu-se que, no caso concreto, o acórdão seguiu a teoria absoluta do conteúdo essencial dos direitos fundamentais, que indica abstratamente o conteúdo essencial do direito fundamental à liberdade de locomoção do adolescente, independentemente das circunstâncias do caso em particular, em conformidade com as restrições da norma infraconstitucional que explicitava os casos de internação e com o entendimento sumulado dos Tribunais, que desobriga a restrição do direito no caso em análise.

Palavras-chave: Ato Infracional. Direitos Fundamentais. Dignidade da pessoa humana. Doutrina da proteção integral. Direito à liberdade de locomoção. Habeas corpus.

Abstract: This is a study of a favorable decision for an adolescent to whom the socioeducational measure of hospitalization had been applied, for having committed an infraction similar to the traffic of narcotics. The parameter of this analysis is the fundamental right to freedom of movement, and the theory of essential content of fundamental rights. It examines the right to freedom of movement based on the Doctrine of Integral Protection, which gives adolescents priority in the protection of Fundamental Rights. It was observed that the decision followed the strict interpretation of the infraconstitutional norm regulating obedience to the constitutional principle of exceptionality 
when applying, to any child or adolescent, any deprivation of freedom. It was concluded that in this case, the judgment followed the absolute theory of the essential content of fundamental rights, which abstractly indicates the essential content of the fundamental right to freedom of movement of the adolescent, regardless of the circumstances of the particular case, in accordance with the restrictions of the infraconstitutional norm that explained cases of hospitalization, and the summary opinion of the Courts, which rules that the restriction of the right, in this particular case, is not required.

Keywords: Offense. Essential Content of Fundamental Rights. Human Dignity. Doctrine of Integral Protection. Right to Freedom of Movement.

Resumen: Se trata del estudio de una decisión favorable a un adolescente al que se le había aplicado medida socioeducativa de internación por la práctica de acto infraccional equiparado al tráfico de estupefacientes. El análisis tuvo como parámetro el derecho fundamental a la libertad de circulación y a la teoría del contenido esencial de los derechos fundamentales. Se examinó el derecho a la libertad de circulación a partir de la Doctrina de la Protección Integral, que le concede al adolescente la prioridad en la protección de los Derechos Fundamentales. Se observó que la decisión siguió la interpretación estricta de la norma infraconstitucional reglamentaria de la obediencia al principio constitucional de la excepcionalidad cuando se le aplica, al niño o al adolescente, cualquier medida privativa da libertad. Se concluyó que, en este caso concreto, la decisión siguió la teoría absoluta del contenido esencial de los derechos fundamentales, que indica de modo abstracto el contenido esencial del derecho fundamental a la libertad de circulación del adolescente, independientemente de las circunstancias del caso en particular, en conformidad con las restricciones de la norma infraconstitucional que explicitaba los casos de internación y con el entendimiento compendiado de los Tribunales, que desobliga la restricción del derecho en el caso en análisis.

Palabras clave: Acto Infraccional. Derechos Fundamentales. Dignidad de la persona humana. Doctrina de la protección integral. Derecho a la libertad de circulación. Habeas corpus. 


\section{INTRODUÇÃO}

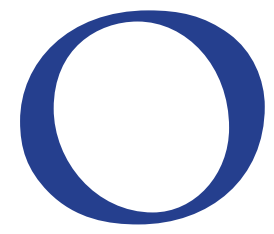

presente artigo tem como objetivo analisar a decisão judicial referente ao habeas corpus (HC) n. 268.489-SP33, impetrado no Superior Tribunal de Justiça (STJ) em favor de pessoa adolescente contra ato do Tribunal de Justiça do Estado de São Paulo (TJSP) que, em sede de apelação, havia mantido medida socioeducativa de internação aplicada pelo juiz de primeiro grau em razão da prática de ato infracional equiparado ao tráfico de entorpecentes. Para motivar a internação, as duas primeiras decisões haviam sido proferidas com base em argumentos referentes às condições socioeconômicas do adolescente, bem como à proteção da saúde da sociedade.

A relevância do tema refere-se à frequência com que pode estar sendo aplicada a medida socioeducativa de internação a adolescentes sem que sejam considerados os princípios fundamentais decorrentes da Doutrina da Proteção Integral, assumida pelo ordenamento jurídico brasileiro na Constituição Federal de 1988 (CF), quais sejam a excepcionalidade e a brevidade da internação, a ponto de a privação de liberdade, em vez de estar contribuindo para os objetivos constitucionais, estaria abrindo espaço para o já superado menorismo.

Como hipótese, considerou-se que os princípios anteriormente mencionados, regulamentados por diversos dispositivos contidos no Estatuto da Criança e do Adolescente, sobretudo por aqueles que explicitam as condições necessárias à aplicação de medida socioeducativa de internação, definem o conteúdo essencial do direito à liberdade de locomoção daquela população no caso em análise, de modo que a internação realizada sem sua estrita observância poderá ferir tal conteúdo.

O método utilizado foi o dedutivo. A metodologia utilizada foi a pesquisa básica, de cunho qualitativo; do ponto de vista dos objetivos, é exploratória; e quanto aos seus métodos, é tanto bibliográfica quanto de estudo de caso.

3 BRASIL. Superior Tribunal de Justiça. Habeas Corpus n. 268.489 - SP (2013/0106538-3). Habeas Corpus Substitutivo de Recurso Próprio. Descabimento. Estatuto da Criança e do Adolescente. Ato Infracional Equiparado a Tráfico Ilícito de Entorpecentes. Medida Socioeducativa de Internação. Gravidade Abstrata do Delito. Enunciado N. 492 da Súmula do STJ. Habeas Corpus não conhecido. Ordem Concedida de Ofício. Relator: Ministra Marilza Maynard (Desembargadora Convocada do TJ/SE), Data de Julgamento: 27/08/2013, T5 - Quinta Turma) 
A primeira parte do artigo apresentou-se o direito fundamental dos adolescentes à liberdade de locomoção, levando-se em conta o tratamento legal especial estabelecido para eles em razão da Doutrina da Proteção Integral, introduzida na $\mathrm{CF}$, em consonância com as diretrizes internacionais de direitos humanos e com o Estado Democrático de Direito.

Na parte seguinte, examinou-se a normativa constitucional e infraconstitucional referente à restrição ao direito de locomoção do adolescente que cometeu ato infracional à luz das teorias absoluta e relativa referentes à garantia essencial dos Direitos Fundamentais, tendo em vista analisar quais seriam as motivações necessárias a uma decisão judicial que realmente tivesse como motivação a estrita preservação do mencionado conteúdo.

Por fim, à luz das doutrinas expostas nas duas primeiras partes do artigo, procedeu-se ao estudo de caso referente ao HC n. 268.489-SP, discutindo-se as motivações fornecidas pelos órgãos de primeira, segunda e terceira instâncias para sua decisão e aferindo-se a aproximação de cada uma delas em relação à garantia do conteúdo essencial do direito fundamental à liberdade de locomoção do adolescente em conflito com a lei no caso analisado.

\section{O DIREITO FUNDAMENTAL À LIBERDADE E A DOUTRINA DA PROTEÇÃO INTEGRAL}

Inicialmente, cabedelimitarqueos direitosfundamentaissãoconsiderados, neste artigo, como normas jurídicas positivas de natureza principiológica: "os direitos fundamentais podem ser definidos como os princípios jurídica e positivamente vigentes em uma ordem constitucional que traduzem a concepção de dignidade humana de uma sociedade e legitimam o sistema jurídico estatal". ${ }^{4}$

Ressalta-se também que o direito fundamental à liberdade se encontra positivado na CF, embora não se negue a existência de outros direitos fundamentais em sentido material, os quais estão nela implícitos, que derivam dos primeiros ou constam das normas de direito internacional aplicáveis ao ordenamento jurídico do Estado. ${ }^{5}$

4 LOPES, Ana Maria D'Ávila. Os direitos fundamentais como limites ao poder de legislar. Porto Alegre: Sérgio Antônio Fabris, 2001, p. 35.

5 CANOTILHO, José Joaquim Gomes. Direito constitucional e Teoria da Constituição. Coimbra: Almedina, 1998. 
De fato, a CF também prevê a aplicação de direitos fundamentais em sentido material, no $\S 2^{\circ}$ do art. $5^{\circ}$, o qual estabelece que os direitos fundamentais não previstos na mesma "não excluem outros decorrentes do regime e dos princípios por ela adotados, ou dos tratados internacionais em que a República Federativa do Brasil seja parte", os quais formam um bloco de constitucionalidade.

Quanto a estes últimos, cabe afirmar a importância, para a história dos direitos fundamentais das crianças e dos adolescentes, da Declaração Universal dos Direitos da Criança pela Assembléia Geral das Nações Unidas em 1959 e a Convenção sobre os Direitos da Criança adotada pela Organização das Nações Unidas em 1989, que foi ratificada no Estado brasileiro em 1990, valendo salientar que Convenção define como criança todo ser humano com menos de 18 anos de idade, a não ser que a legislação aplicável no país considere outra a maioridade. ${ }^{6}$

Os direitos humanos previstos na Convenção sobre os direitos da Criança abarcam todas as áreas tradicionalmente definidas como direitos humanos, considerando-os indivisíveis e de igual importância, uma vez que "acolhe a concepção do desenvolvimento integral da criança, reconhecendo-a como verdadeiro sujeito de direito, a exigir proteção especial e absoluta prioridade".

Tal reconhecimento dos direitos humanos das crianças e dos adolescentes como sujeitos de direitos foi resultado de uma longa trajetória histórica que partiu da indiferença legal e social acerca de sua condição especial e passou por um período que ficou conhecido entre os estudiosos como Doutrina da Situação Irregular ou menorismo e foi adotada oficialmente no Brasil pela Lei n. 6.697/1979, o Código de Menores, o qual "desconsiderava a qualidade de sujeitos de direitos das crianças e dos adolescentes, limitando-se apenas a tratar das situações contrárias à lei, no intuito de separá-los da sociedade". ${ }^{8}$

De acordo com a antiga Doutrina da Situação Irregular, se as condições da criança ou do adolescente fossem consideradas precárias sob os aspectos sociais,

6 ORGANIZAÇÃO DAS NAÇÕES UNIDAS. Declaração Universal dos Direitos das Crianças de 1959. Disponível em: <http://www.mp.rs.gov.br/infancia/documentos_internacionais/ id90.htm>. Acesso em: 05 out.2013. ORGANIZAÇÃO DAS NAÇÕES UNIDAS. Declaração Universal dos Direitos Humanos de 1948. Disponível em: <http://www.unicef.org/brazil/pt/resources_10133.htm>. Acesso em: 05 out. 2013.

7 PIOVESAN, Flávia. Temas de direitos humanos. 6. ed. São Paulo: Saraiva, 2013, p. 411.

8 LOPES, Ana Maria D'Ávila. Os direitos fundamentais como limites ao poder de legislar. p. 109. 
econômicos e familiares, o órgãojudicial teria amplo poder para suprir a deficiência de políticas públicas utilizando-se da internação nos mesmos estabelecimentos destinados àqueles que cometiam atos infracionais, sob o manto da prestação de assistência àquela população, judicializando, portanto, os problemas sociais, em prejuizo do seu direito à liberdade de locomoção. ${ }^{9}$

A Doutrina da Proteção Integral, ao afirmar a condição de sujeito de direito às crianças e aos adolescentes, veio não somente afirmar para eles os direitos reconhecidos pela Declaração Universal dos Direitos Humanos para todas as pessoas, como especificar sua condição especial e prioritária de pessoa em desenvolvimento. Tais considerações encontram-se expressas em outros documentos internacionais como as Regras Mínimas da Nações Unidas para a Justiça da Infância e da Juventude, conhecidas como Regras de Beijing; as Diretrizes das Nações Unidas para a Prevenção da delinquência Juvenil, conhecidas como Diretrizes de Riad; as Regras Mínimas das Nações Unidas para a elaboração de Medidas Não Privativas de Liberdade, conhecidas como Regras de Tóquio; e as Regras Mínimas das Nações Unidas para a Proteção dos Jovens Privados de Liberdade ${ }^{10}$ (VOLPI, 1998).

Pode-se afirmar que esse corpo de legislação internacional superou tanto politicamente quanto juridicamente o tratamento anteriormente dispensado às crianças e aos adolescentes autores de atos infracionais, limitando o poder estatal na aplicação das medidas restritivas e privativas de liberdade nos Estados que aderiram à Doutrina da Proteção Integral, como é o caso do Brasil.

Assim, a CF trata especificamente da proteção especial que deve ser assegurada às crianças, aos adolescentes e aos jovens pela família, pela sociedade e pelo Estado, inclusive colocando-os a salvo da equiparação anteriormente feita pelo Poder Judiciário com os adultos quando do cometimento de qualquer delito. Nessa esteira, a Lei n. 8.069 de 13 de julho de 1990, o Estatuto da Criança e do Adolescente (ECA), enumera uma série de direitos fundamentais previstos constitucionalmente 9 SARAIVA, João Batista Costa. Adolescente em conflito com a lei: da indiferença à proteção integral. Uma abordagem sobre a responsabilidade penal juvenil. Porto Alegre: Livraria do Advogado, 2009.

10 VOLPI, Mário. Adolescentes privados da liberdade: a normativa nacional e internacional. São Paulo: Cortez, 1998. 
para os adultos, mas aplicáveis à população, mas dispõe acerca de outros que são próprios da sua condição especial de pessoa em desenvolvimento.

Com relação ao direito fundamental à liberdade, este se apresenta como uma construção jurídica que se ampliou gradativamente, em contextos históricos caracterizados por lutas em defesa do bem comum, como explicitam as primeiras palavras da Declaração Universal dos Direitos do Homem, em seu art. 10: "Todas as pessoas nascem livres e iguais em dignidade e direitos. São dotadas de razão e consciência e devem agir em relação uma às outras com espírito de fraternidade".

No ordenamento jurídico brasileiro, o direito fundamental à liberdade é estabelecido constitucionalmente de diversas formas, como a liberdade de locomoção, de pensamento, de opinião, de religião e de consciência, por exemplo, sendo que a liberdade de locomoção, tratada nesse artigo, representa o direito do indivíduo de ir, vir, ficar, permanecer, bem como de circular pelas vias públicas.

Além do dispositivo mencionado, há outros dispositivos constitucionais que também tutelam o direito fundamental à liberdade de locomoção, ainda que o façam indiretamente, a exemplo daquele que veda a prisão ilegal, os quais apresentam força normativa que atinge tanto o Estado, informando suas atividades políticas, administrativas, judiciais e legislativas; como os particulares, evidenciando a eficácia horizontal dos direitos fundamentais.

Por outro lado, é importante observar que o direito fundamental à liberdade de locomoção não é um direito ilimitado, mas passível de restrições. Em algumas circunstâncias, a própria CF autoriza sua restrição de forma imediata, ou seja, por meio de disposições previstas diretamente no corpo constitucional, ao passo que, em outras situações, tal restrição ocorre de forma mediata, por autorização expressa ou tácita ao legislador ordinário.

OECA dispõe acerca da liberdade de locomoção das crianças e dos adolescentes, ressalvando-se as restrições legais, como aquela que proíbe qualquer criança ou adolescente nascido no território nacional de sair do país sem prévia e expressa autorização judicial, na companhia de estrangeiro residente ou domiciliado no exterior (art. 16). Nesse caso, a restrição à liberdade de locomoção tem como objetivo proteger a criança e o adolescente contra perigos rotineiros, a exemplo 
do tráfico interestadual e internacional de menores para alimentar a prostituição infantojuvenil e do mercado criminoso da venda de órgãos.

Assim também o Estado pode impor medidas restritivas da liberdade de locomoção à criança e ao adolescente por razões protetivas ou visando resguardar a ordem pública e os direitos fundamentais alheios, violados ou ameaçados de violação em face de conduta do próprio menor, que tenha contrariado os preceitos da lei penal, sendo uma dessas restrições a privação de liberdade do adolescente a quem se atribui a prática de ato infracional.

Antes de adentrar o tema da prática de ato infracional e da aplicação das medidas socioeducativas, é importante ressaltar que a inimputabilidade penal dos menores estabelecida pela CF não afasta a responsabilidade deles pela prática de fatos típicos, antijurídicos e culpáveis que eles venham a cometer, ressalvandose apenas a ausência de responsabilidade dos menores de 12 anos, aos quais se aplicam somente as medidas protetivas enumeradas no art. 101 do ECA.

Em decorrência da responsabilidade anteriormente mencionada, se um adolescente, consideradomenordeidadesegundooordenamentojurídicobrasileiro, praticar algum ato infracional, definido pelo ECA como conduta equivalente a crime ou a contravenção penal, será por isso responsabilizado, podendo-Ihe ser aplicada desde a medida socioeducativa de advertência até as medidas socioeducativas de semiliberdade ou de internação, que consistem, respectivamente, na privação parcial ou total de sua liberdade, que pode durar até três anos.

Entretanto, antes da aplicação de qualquer medida socioeducativa, são reconhecidas aos adolescentes aos quais se atribuem a prática de ato infracional, dentre outras, as garantias do devido processo legal; do contraditório; da ampla defesa; da presunção do estado de inocência; do juízo natural; da proibição de provas ilícitas; da proibição de apreensão sem que haja flagrante delito ou ordem judicial escrita e fundamentada; do respeito ao princípio legalidade; e da presunção do estado de inocência.

Além disso, a escolha da medida socioeducativa a ser aplicada ao adolescente deve ser pautada nas condições de adequação à proteção e a socioeducação dele 
e, ao mesmo tempo, à preservação da ordem pública e dos direitos alheios. Além disso, deve ser estritamente necessária, somente aplicável diante da ineficácia das demais espécies de medidas e, ainda, proporcional à gravidade do fato e à lesão jurídica produzida.

Acerca da privação de liberdade do adolescente pela prática de ato infracional, a CF estabelece como critérios limitadores da sua aplicação "a excepcionalidade, a brevidade e o respeito à condição de pessoa em desenvolvimento" dessa população (art. 227, § $3^{\circ}$., inciso V).

A regra constitucional da excepcionalidade da internação é regulamentada pelo ECA (art. 122), que estabelece condições específicas para a restrição ao seu direito à liberdade, como a prática de violência ou grave ameaça, bem como a reiteração no cometimento de outras infrações graves ou pelo descumprimento de medida anteriormente imposta.

Ressalte-se ainda que, como reflexo imediato da doutrina da proteção integral assumida pelo Estado brasileiro na CF, os critérios da absoluta prioridade e do melhor interesse da criança e do adolescente impedem que estes venham a receber um tratamento mais rigoroso do que aquele previsto para o adulto.

Feitas as considerações referentes ao direito à liberdade de locomoção e às restrições a esse direito fundamental no caso de cometimento de ato infracional por adolescentes, passa-se neste item ao exame das doutrinas referentes ao conteúdo essencial dos direitos fundamentais para que, na terceira parte deste artigo, possa-se chegar à discussão acerca da preservação do conteúdo essencial do direito fundamental à liberdade dos adolescentes no caso da prática do ato infracional análogo ao tráfico de entorpecentes.

\section{A GARANTIA DO CONTEÚDO ESSENCIAL DOS DIREITOS FUNDAMENTAIS E SUA APLICABILIDADE AO DIREITO À LIBERDADE DO ADOLESCENTE QUE COMETEU ATO INFRACIONAL}

A normativa disposta no Título III do ECA prevê apreensão e internação de adolescentes em Unidades de Internação, em razão de flagrante na prática de ato 
infracional ou de decisão judicial, respectivamente, o que constitui uma limitação ao exercício do direito à liberdade de locomoção por parte dessa população.

Por outro lado, a norma constitucional estabelecida no inciso III do $\S .3^{\circ}$ do art. 227 da CF, regulamentada no art. 122 do ECA, constitui um limite ao limite de exercício ao direito de locomoção do adolescente que cometeu ato infracional, uma vez que condiciona a internação aos seguintes casos: a) tratar-se de ato infracional cometido mediante grave ameaça ou violência a pessoa; b) por reiteração no cometimento de outras infrações graves; c) por descumprimento reiterado e injustificável de medida anteriormente imposta. Ressalte-se que, em nenhuma hipótese, será aplicada a internação, havendo outra medida adequada, o que demonstra que esta medida deve ser utilizada como última ratio do sistema, tal como acontece com a prisão preventiva (art. 282, § 6 , Código de Processo Penal).

Ao estipular situações específicas nas quais cabe a internação, regulamentando a norma constitucional que estabelece a excepcionalidade e a brevidade da internação de adolescentes pela prática de ato infracional, a legislação infraconstitucional apresenta-se como regra que defende o conteúdo essencial do direito de locomoção dessa população.

Portanto, o adolescente que cometeu ato infracional permanece com seu direito à liberdade, sendo este protegido porque a internação ficou condicionada aos casos em que o legislador infraconstitucional dispôs, cabendo ao aplicador examinar cuidadosamente o caso concreto sob pena de estar ferindo o conteúdo essencial do direito fundamental de locomoção do adolescente. Portanto, é pertinente se indagar qual seria o núcleo essencial desse direito que o legislador protegeu quando especificou os casos de internação. Ressalta-se aqui a importância da pergunta, cuja resposta poderá auxiliar o aplicador da norma a aplicá-la com maior segurança jurídica. Para tanto, faz-se necessário um esforço no sentido de expor, ainda que brevemente, a doutrina do conteúdo essencial dos direitos fundamentais e explicitar a posição adotada na análise que será feita a seguir.

Inicialmente, faz-se necessário ressaltar que, assim como acontece com o conceito de direitos humanos, não existe consenso doutrinário acerca do critério 
de determinação do conteúdo essencial dos direitos fundamentais, tampouco acerca de seu conceito. A proteção de tal conteúdo foi, a princípio "criada para controlar a atividade legislativa em ordenamentos que não previam o controle de constitucionalidade da leis"11, sendo utilizada também para defender os direitos fundamentais de excessos ou faltas cometidas na atividade jurisprudencial, limitando os possíveis limites opostos à sua concretização.

A consideração de tal conteúdo tem a finalidade de evitar que a restrição na aplicação dos direitos fundamentais fique inteiramente nas mãos do Poder Público, o que se daria, por exemplo, se o legislador dispusesse que toda prática de ato infracional resultasse, necessariamente, na internação do adolescente, ou se o Poder Judiciário considerasse da mesma forma, solapando a excepcionalidade da internação prevista constitucionalmente. Trata-se, portanto, de um limite que nem o legislador, nem o aplicador da lei pode ultrapassar sem ferir o conteúdo material da CF.

Sendo assim, deve ser determinado qual é o conteúdo essencial de um direito fundamental. A construção doutrinária varia ao fornecer parâmetros para tal determinação. Dentre as doutrinas mais conhecidas destaca-se a posição de Smend, que, com seu método integrativo ou científico-espiritual de interpretação do direito, defende que o conteúdo essencial de um direito fundamental depende unicamente dos valores socialmente compartilhados pelos membros de uma nação e abre espaço para construção de uma teoria absoluta e uma teoria relativa sobre ele. ${ }^{12}$

A teoria de Smend foi construída em um contexto histórico de transição na Alemanha após a Primeira Guerra Mundial. Smend viu os direitos fundamentais como meios juridicamente aptos para se requerer que o sistema da política republicano adotasse programações decisórias para compensar a exclusão social e aproximar os indivíduos do Estado. Assim, tratou os direitos fundamentais como um sistema de valores que salvaguardavam o conteúdo essencial da Constituição ${ }^{13}$.

Naquele contexto, Smend introduziu o estudo dos direitos fundamentais no Direito Constitucional a partir do seu conteúdo material, que nem sempre iria coincidir com a fórmula legislativa, ou pode levar os partidários de sua teoria 11 LOPES, Ana Maria D'Ávila. Os direitos fundamentais como limites ao poder de legislar, p. 167.

12 SMEND, Rudolf. Constituzione e diritto constituzionale. Madrid: Aguilar, 1970.

13 FELLET, André Luiz Fernandes. Rudolf Smend e os direitos fundamentais como ordem objetiva de valores. Revista do Instituto de Direito Brasileiro, Lisboa, Ano 1 (2012), n. 11, p. 6605-6634. 
a defender que o conteúdo essencial dos direitos fundamentais decorre de um sistema único de valores e bens, que no caso de um Estado irá promover sua integração material e política.

A teoria absoluta considera o conteúdo essencial dos direitos fundamentais sempre o mesmo, independente do caso concreto, não sendo admitida qualquer ação legislativa ou intervenção estatal capaz de ultrapassar seus limites, ainda que isso seja feito para defender outros direitos fundamentais de mesma hierarquia. É, portanto, determinado em abstrato e não passível de ponderação ou proporcionalidade com outros direitos durante sua aplicação, embora haja quem defenda, ao lado de um conteúdo absoluto estático, a existência de um conteúdo absoluto dinâmico em relação ao tempo, mas não em relação a urgências ou contingências. ${ }^{14}$

Em posição contrária à teoria absoluta do conteúdo essencial dos direitos fundamentais encontra-se a teoria relativa, que o define segundo as exigências dos valores ou dos interesses do caso concreto, mediante o uso da ponderação e da proporcionalidade, tendo em vista o objetivo perseguido pela norma restritiva. Trata-se, portanto, de um conteúdo não fixo nem preestabelecido, podendo variar em consequência de sopesamento, buscando-se a máxima proporcionalidade, mas tomando cuidado apenas de não Ihe conferir uma excessiva flexibilidade, capaz de gerar insegurança jurídica. ${ }^{15}$

A par das dificuldades encontradas ao tentar estabelecer um conceito único para o conteúdo essencial dos direitos fundamentais, há ainda aqueles formulados por Günther Dürig e por Peter Häberle. Para Dürig, há confusão entre o conteúdo material de um direito fundamental e a dignidade humana, ao passo que, na visão de Häberle ${ }^{16}$, os direitos fundamentais são bens jurídicos constitucionais que não incluem não apenas os bens individuais, mas também os da coletividade. ${ }^{17}$

A teoria do conteúdo essencial dos direitos fundamentais desenvolvida por Dürig na Alemanha afirma que tal conteúdo corresponde à dignidade da pessoa

14 SAMPAIO, Marcos. O conteúdo essencial dos direitos sociais. São Paulo: Saraiva, 2013.

15 ALEXY, Robert. Teoria dos direitos fundamentais. São Paulo: Malheiros, 2011

16 HÄBERLE, Peter. La garantia del contenido essencial de los derechos fundamentales. Madrid: Dykinson, 2003.

17 LOPES, Ana Maria D'Ávila. Os direitos fundamentais como limites ao poder de legislar, p. 180. 
humana, que "poderia ser considerada atingida sempre que a pessoa concreta (o indivíduo) fosse rebaixada a objeto" ${ }^{18}$, devendo o Estado garantir seu tratamento como sujeito de direitos, ou seja, que ele (o indivíduo) possa exercer seus direitos sempre que seus pressupostos e condições sejam cumpridos.

A Constituição alemã (1949), bem como a portuguesa, (1976) e a espanhola (1978), influenciaram o constitucionalismo brasileiro, tanto com o papel dos direitos fundamentais como com a importância concedida ao princípio da dignidade humana. Sendo assim, tal princípio está inscrito no inciso III do artigo $1^{\circ}$ da CF como fundamento da República Federativa do Brasil. "A supremacia da constituição se inicia por seus princípios fundamentais, tendo como centro a dignidade do ser humano. Não como critérios somente interpretativos, mas sim como normas constitucionais, incondicionalmente determinantes no sistema brasileiro"19.

Quanto ao critério utilizado para determinação do conteúdo essencial dos direitos fundamentais, existe uma posição objetiva que analisa os direitos fundamentais com base no significado desse direito para a vida da coletividade, de modo que um direito pode deixar de "ser aplicado a um particular, sem que isso afete o conteúdo essencial, mas sempre que continue vigente para as demais pessoas"20, e uma posição subjetiva, que protege o indivíduo como alvo dos direitos fundamentais, de modo que sua restrição para ele chega a afetar seu conteúdo, que não pode ser sacrificado em caso nenhum.

Por fim, a concepção de Peter Häberle ${ }^{21}$ acerca do conteúdo essencial dos direitos fundamentais tenta conciliar o interesse subjetivo individual com o interesse objetivo institucional por intermédio de um equilíbrio harmônico entre eles, a ser realizado pelo legislador que, no caso, cria direito, ao delimitar seus contornos. ${ }^{22}$

18 SARLET, Ingo Wolfgang. As dimensões da dignidade da pessoa humana. Revista Brasileira de Direito Constitucional, São Paulo, n. 09, jan./jun. 2007, p. 380.

19 PIOVESAN, Flávia. Temas de direitos humanos. p. 504.

20 LOPES, Ana Maria D'Ávila. A garantia do conteúdo essencial dos direitos fundamentais. Revista de Informação Legislativa, Brasília a. 41 n. 164, p. 7-15, out./dez. 2004.

21 HÄBERLE, Peter. La garantia del contenido essencial de los derechos fundamentales

22 SAMPAIO, Marcos. 0 conteúdo essencial dos direitos sociais 


\section{A GARANTIA DO CONTEÚDO ESSENCIAL DO DIREITO DE LIBERDADE DE LOCOMOÇÃO DO ADOLESCENTE: ANÁLISE DO ACÓRDÃO}

O Estado brasileiro, apesar da subscrição aos tratados e ao modelo internacional imposto pelas Nações Unidas de contenção ou eliminação do uso e da venda de drogas, tem enfrentado graves problemas de segurança e saúde pública decorrentes do mercado ilícito de tais substâncias, sendo que nos últimos anos tem-se observado a frequente participação de adolescentes no mencionado comércio.

O HC n. 268.489-SP, cuja relatora foi a Sra. Min. Marilza Maynard, foi votado à unanimidade pela $5^{\text {a }}$ Turma do STJ e teve como paciente um adolescente privado de liberdade em razão do tráfico de entorpecentes. Eis a ementa:

Habeas Corpus substitutivo de recurso próprio. Descabimento. Estatuto da Criança e do Adolescente. Ato infracional equiparado a tráfico ilícito de entorpecentes. Medida socioeducativa de internação. Gravidade abstrata do delito. Enunciado n. 492 da Súmula do stj. Habeas corpus não conhecido. Ordem concedida de ofício. 1. Este Superior Tribunal de Justiça, na esteira do entendimento firmado pelo Supremo Tribunal Federal, tem amoldado o cabimento do remédio heróico, adotando orientação no sentido de não mais admitir habeas corpus substitutivo de recurso ordinário/especial. Contudo, à luz dos princípios constitucionais, sobretudo o do devido processo legal e da ampla defesa, tem-se analisado as questões suscitadas na exordial a fim de se verificar a existência de constrangimento ilegal para, se for o caso, deferir-se a ordem de ofício. 2. Constata-se a insuficiência da motivação apresentada para a imposição da medida mais gravosa, tendo por base apenas a gravidade abstrata do ato infracional, praticado sem violência ou grave ameaça, e a existência de uma única anotação criminal em desfavor do adolescente infrator. 3. Habeas corpus não conhecido. Ordem concedida de ofício para determinar que o Juiz de primeiro grau profira outra decisão aplicando medida socioeducativa diversa da internação, assegurado ao paciente o direito de aguardar em liberdade assistida novo pronunciamento.

De acordo com o inciso XLIII do art. $5^{\circ}$ da CF, o tráfico de entorpecentes e drogas afins é considerado crime inafiançável, insuscetível de graça ou anistia por ele "respondendo os mandantes, os executores e os que, podendo evitá-los, se omitirem". 
Por outro lado, o STJ promulgou, no ano de 2012, a Súmula n. 492, cujo enunciado é o seguinte: "O ato infracional análogo ao tráfico de drogas, por si só, não conduz obrigatoriamente à imposição de medida socioeducativa de internação do adolescente". Para chegar a esse enunciado, os ministros do STJ se utilizaram de decisões anteriores que concluíram pela não obrigatoriedade da internação apenas pelo efetivo cometimento do ato infracional análogo ao tráfico de entorpecentes.

Em seu voto, a Sra. Ministra Marilza Maynard transcreveu um trecho daquela decisão prolatada pelo juiz de primeiro grau, do qual foram aqui extraídos três pontos para discussão:

O adolescente "estava fora da escola, usava maconha e cocaína, não estava profissionalizado"; 2 "A medida de internação tem cabimento no tráfico de adolescentes porque a infração tem como objetividade jurídica a saúde pública representada pela vida e saúde de um número indeterminado de pessoas. Se a violência ou grave ameaça à saúde de uma pessoa autoriza a internação, com mais razão a autoriza a de um número indeterminado de pessoas"; 3 .

"Ele já praticou outro (delito). Em liberdade, com certeza, voltará a delinquir, mesmo porque não tem ambiente familiar e social para se recuperar. Por isso não poderá apelar em liberdade".

Conforme a proposta deste artigo, trata-se de buscar como substrato as teorias do conteúdo essencial dos direitos fundamentais que foram aqui expostas, para encontrar aquela consonante à decisão pela manutenção ou não da privação da liberdade do adolescente no caso concreto.

De acordo com o estabelecido no corpo do acórdão, o juiz de primeiro grau considerou a situação social do adolescente e a prática anterior de outro delito, o que, a seu ver, favorecia, respectivamente, o uso da droga como também a possibilidade de permanecer servindo ao tráfico, favorecendo ainda a exposição de um número indeterminado de pessoas ao seu uso. Assim motivou sua opção por restringir seu direito à liberdade de locomoção.

Da decisão proferida em segundo grau, que acompanhou a decisão de primeiro grau, destacam-se na presente análise três pontos extraídos da transcrição feita 
pela Ministra Marilza Maynard no corpo de seu voto, os quais se afiguram, estes sim, como razões condizentes com a Doutrina da Proteção Integral e a proteção do direito de locomoção do adolescente:

"Na hipótese, o adolescente demonstrou ousadia e sério envolvimento com o comércio ilícito, não possuindo, portanto, condições de recuperarse sem a submissão à medida extrema. Configurada, portanto, a excepcionalidade a que se refere o art. 121 caput, do Estatuto da Criança e do Adolescente."; 2. "Por outro lado, o ato infracional equivalente ao crime de tráfico de drogas é gravíssimo, equiparado a crime hediondo (art. $2^{\circ}$. da Lei 8.072/90) e, embora realizado sem violência ou grave ameaça à pessoa, demonstra expressiva lesividade social, enquadrandose na hipótese permissiva do art. 122, I do ECA"; 3. "Ressalte-se, ainda, que o menor é usuário de maconha e cocaína há dois anos, não estuda e não possui respaldo familiar, além de responder também por outro ato infracional".

Por fim, o voto da Ministra Marilza Maynard determinou que o juiz de primeiro grau proferisse nova sentença e, aplicando medida socioeducativa diversa da internação e assegurando ao paciente o direito de aguardar em liberdade assistida a nova decisão, uma vez que considerou insuficiente a motivação apresentada para imposição da medida mais gravosa, tendo por base apenas a gravidade abstrata do ato infracional, praticado sem violência ou grave ameaça, e a existência de uma única e anotação criminal em desfavor do adolescente infrator.

Na decisão, a Ministra arguiu ainda o enunciado sumular n. 492 do Superior Tribunal de Justiça, pelo qual "o ato infracional análogo ao tráfico de drogas, por si só, não conduz obrigatoriamente à imposição de medida socioeducativa de internação do adolescente".

A posição adotada na decisão do Superior Tribunal de Justiça garantiu a aplicação da Constituição e das normas ordinárias, preservando o conteúdo essencial do direito fundamental à liberdade de locomoção previsto para a população de adolescentes quando da prática de ato infracional, em cumprimento à sua função: "Ao legislador cabe eleger a qualidade e quantidade da sanção; enquanto ao juiz cabe estabelecer a relação entre a natureza da sanção e a gravidade do delito". ${ }^{23}$

23 FERRAJOLI, Luigi. Direito e razão: teoria do garantismo penal. 2. ed. São Paulo: RT, 2006, p. 366. 
A medida socioeducativa de internação não é a única cabível, e a Súmula n. 492 do STJ não permite um tratamento mais rigoroso aos menores do que aquele dado aos maiores pela legislação e jurisprudência pátrias. Assim, o poder conferido à jurisdição não pode extrapolar determinados limites para permitir decisões contra ou extra legem sem fundamentação adequada, sem a criteriosa análise do caso concreto ou sem uma argumentação jurídica sólida. ${ }^{24}$

Ademais, "ainda que o ordenamento jurídico seja pouco preciso ou explícito em termos conceituais, não há nenhuma razão para subtrair ao adolescente, ou mitigar de qualquer forma, a inteira prática dos princípios assecuratórios da liberdade individual instituídos pela ordem constitucional". ${ }^{25}$

O ordenamento jurídico brasileiro não definiu expressamente o núcleo dos direitos fundamentais, mas o modelo constitucional garantístico e as normas infraconstitucionais que delimitam a privação de liberdade denotam o cuidado pela sua proteção, ou seja, para que tais direitos não sejam inteiramente prejudicados, o que se observa também pelo estabelecimento das cláusulas pétreas contra restrições abusivas deles. ${ }^{26}$

O tráfico de drogas por adolescentes é uma conduta que grande parte da sociedade considera um risco para eles próprios, pois os coloca à mercê de possíveis violências de seus mandantes e por isso argumenta a favor de sua internação sumária, embora se possa argumentar que o problema do adolescente que se envolve no consumo e no tráfico de drogas está mais relacionado a questões sociais passíveis de serem resolvidas sem privação de liberdade.

De fato, as preferências por uma política criminal de privação de liberdade do adolescente por um ato infracional fora das prescrições legais afastam-se da Doutrina da Proteção Integral ratificada pelo Estado brasileiro, aproximando-se de um retorno do antigo menorismo e higiene social próprios da Doutrina da Situação Irregular e do antigo Código de Menores, requerendo-se a conciliação entre as dimensões objetiva e subjetiva da garantia do conteúdo essencial do $\overline{24}$ MORAES, Railda Saraiva de. Desenvolvimento e criminalidade. Fortaleza: Universidade Federal do Ceará, 1979.

25 KONZEN, Afonso Armando. Pertinência socioeducativa: reflexões sobre a natureza jurídica das medidas. Porto Alegre: Livraria do Advogado, 2005, p. 70.

26 SAMPAIO, Marcos. 0 conteúdo essencial dos direitos sociais. 
direito à liberdade de locomoção da mencionada população, o que a presente análise não detectou.

Observou-se ainda que o acórdão estudado, além de aproximar-se da dimensão subjetiva do conteúdo essencial do direito fundamental à liberdade do adolescente, praticamente assumiu a teoria absoluta da garantia do mencionado direito, a qual defende "o respeito ao conteúdo essencial do direito fundamental independente do caso concreto, o que implica garantir a existência desse direito sempre, ainda que exista um interesse estatal em conflito". ${ }^{27}$

Sob a ótica da teoria relativa do conteúdo essencial dos direitos fundamentais, tal conteúdo só poderia ser conhecido após a ponderação dos valores e interesses em jogo, o que demandaria o retorno à discussão acerca da proteção da sociedade, resultando na ampliação ou restrição do direito à liberdade do adolescente a fim de evitar uma possível ofensa à unidade entre os princípios constitucionais.

\section{CONSIDERAÇÕES FINAIS}

Em conclusão, observa-se que o acórdão proferido em sede de HC pelo STJ teve como motivação os princípios garantistas estabelecidos pela CF e regulamentados pelos dispositivos infraconstitucionais referentes à restrição de liberdade de locomoção do adolescente pela prática de ato infracional, de modo a observar a proteção ao núcleo essencial do direito restringido.

Vale lembrar que a motivação das decisões judiciais tem uma importância primordial para firmar mudanças paradigmáticas no tratamento de determinadas questões jurídicas referentes a uma população específica, como é o caso dos adolescentes que, em razão da transformação do tratamento tutelar para a proteção integral, foram reconhecidos como sujeitos de direitos.

Assim ocorre com as razões pelas quais se restringe o direito à liberdade de locomoção do adolescente que comete ato infracional: esta ocorre não por razões socioeconômicas, mas em razão da incidência da norma jurídica sobre o fato, uma vez que a norma existe para ser aplicada àqueles que são sujeitos 27 LOPES, Ana Maria D'Ávila. Os direitos fundamentais como limites ao poder de legislar. p. 175. 
de direitos e deveres, como é o caso daqueles que hoje se encontram sob o tratamento da Doutrina da Proteção Integral e não sob o antigo tratamento tutelar, quando sua liberdade de locomoção era restringida por razões outras que não a lei.

Caso o acórdão obrigasse a internação de adolescentes inobstante à falta de violência ou grave ameaça, estaria impondo a esta população uma medida mais grave que aquela atualmente imposta ao adulto pelo delito análogo e, portanto, indo contra a proteção especial conferida pela Doutrina da Proteção Integral que, em consonância com os instrumentos legais internacionais ratificados pelo Estado brasileiro, afirma a dignidade daquela população como sujeitos de direito.

\section{REFERÊNCIAS}

ALEXY, Robert. Teoria dos direitos fundamentais. São Paulo: Malheiros, 2011.

BRASIL. Constituição (1988). Constituição da República Federativa do Brasil. Brasília: Senado,1988. Disponível em: <http: www. Planalto.gov.bri'>. Acesso em: 05 out.2013.

BRASIL. Estatuto da Criança e do Adolescente (ECA). Lei Federal n. 8069, de 13 de julho de 1990. Disponível em: <http:www.planalto.gov.br>. Acesso em: 05 out.2013.

BRASIL. Superior Tribunal de Justiça. Habeas Corpus n.268.489-SP. Relator: Min. Marilza Maynard. Data do julgamento: 27 ago. 2013. Disponível em: <http://www.stj.gov.br/ jurisprudencia /nova/pesquisa.asp > Acesso em: 05 out. 2013.

BRASIL. Superior Tribunal de Justiça. Súmula n. 492. Brasilia, DF, DJe 13/08/2012, RSTJ vol. 227 p. 951. Disponível em: <http://www.stj.jus.br>. Acesso em: 05 out.2013.

BRASIL. Supremo Tribunal Federal. Habeas Corpus n. 84.218-6-SP. Relator: Ministro Joaquim Barbosa. Data do julgamento: 24 nov. 2004. Disponível em: <http://www.stf.gov.br/ jurisprudencia /nova/pesquisa.asp> Acesso em: 05 out. 2013.

CANOTILHO, José Joaquim Gomes. Direito constitucional e teoria da constituição. Coimbra: Almedina, 1998.

FELLET, André Luiz Fernandes. Rudolf Smend e os direitos fundamentais como ordem objetiva de valores. Revista do Instituto de Direito Brasileiro, Lisboa, Ano 1 (2012), n. 11.

FERRAJOLI, Luigi. Direito e razão: teoria do garantismo penal. 2. ed. São Paulo: RT, 2006. 
HÄBERLE, Peter. La garantia del contenido essencial de los derechos fundamentales. Madrid: Dykinson, 2003.

KONZEN, Afonso Armando. Pertinência socioeducativa: reflexões sobre a natureza jurídica das medidas. Porto Alegre: Livraria do Advogado, 2005.

LOPES, Ana Maria D'Ávila. Os direitos fundamentais como limites ao poder de legislar. Porto Alegre: Sérgio Antônio Fabris, 2001.

LOPES, Ana Maria D'Ávila. A Garantia do Conteúdo Essencial dos Direitos Fundamentais. Revista de Informação Legislativa, Brasília a. 41 n. 164, p. 7-15, out./dez. 2004.

MORAES, Railda Saraiva de. Desenvolvimento e criminalidade. Fortaleza: Universidade Federal do Ceará, 1979.

ORGANIZAÇÃO DAS NAÇÕES UNIDAS. Declaração Universal dos Direitos das Crianças de 1959. Disponível em: <http://www.mp.rs.gov.br/infancia/ documentos_internacionais/id90. htm >. Acesso em: 05 out.2013.

ORGANIZAÇÃO DAS NAÇÕES UNIDAS. Declaração Universal dos Direitos Humanos de 1948. Disponível em: <http://www.unicef.org/brazil/pt/ resources_10133.htm>. Acesso em: 05 out. 2013. PIOVESAN, Flávia. Temas de direitos humanos. 6. ed. São Paulo: Saraiva, 2013.

SARAIVA, João Batista Costa. Adolescente em conflito com a lei: da indiferença à proteção integral. Uma abordagem sobre a responsabilidade penal juvenil. Porto Alegre: Livraria do Advogado, 2009.

SAMPAIO, Marcos. O conteúdo essencial dos direitos sociais. São Paulo: Saraiva, 2013.

SMEND, Rudolf. Constituzione e diritto constituzionale. Madrid: Aguilar, 1970.

SARLET, Ingo Wolfgang. As dimensões da dignidade da pessoa humana. Revista Brasileira de Direito Constitucional, São Paulo, n. 09, jan./jun. 2007.

VOLPI, Mário. Adolescentes privados da liberdade: a normativa nacional e internacional. São Paulo: Cortez, 1998. 